\title{
Mortality in Patients of COVID-19 Infection: Biochemical Markers and its Cut-off Values for Predicting Outcome
}

\author{
Muhammad Nadeem Yousaf, Shahid Sarwar, Shandana Tarique, Mukhtar Ahmed and Hassan Tahir \\ Department of Medicine, Allama Iqbal Medical College / Jinnah Hospital, Lahore, Pakistan
}

\begin{abstract}
Objective: To determine the efficacy and cut-off values of C-reactive protein (CRP), lactate dehydrogenase (LDH), serum ferritin, and D-dimer for predicting mortality of COVID-19 infection.

Study Design: Observational study.

Place and Duration of Study: Department of Medicine, Jinnah Hospital, Lahore from January to May 2021.

Methodology: Serum CRP, LDH, ferritin, and D-dimer were measured in patients with moderate to severe COVID-19 infection at admission. Patients were followed for in-hospital disease outcome. ROC curve was used to determine area under curve (AUC) and cut-off values of biomarkers, followed by multi-variate analysis by logistic regression.

Results: In 386 patients, male to female ratio was 1.47/1 (230/156); and mean age was $54.03 \pm 16.2$ years. Disease was fatal in 135 (35\%) patients. AUC for mortality was 0.730 for LDH, 0.737 for CRP, 0.747 for ferritin and 0.758 for D-dimer. Mortality was higher with $\mathrm{LDH} \geq 400 \mathrm{U} / \mathrm{ml}$, Odds Ratio (OR) 5.37 (95\% Cl 3.01-9.57: $\mathrm{p}=0.001)$, CRP $\geq 30 \mathrm{ng} / \mathrm{L}, \mathrm{OR} 4.30$ (95\% Cl 2.11-8.74: $\mathrm{p}=<0.001)$, serum ferritin $\geq 200 \mathrm{ng} / \mathrm{ml}$, OR $4.13(95 \% \mathrm{Cl} 1.05-16.2: \mathrm{p}=0.02)$, and D-dimer $\geq 400 \mathrm{ng} / \mathrm{ml}, \mathrm{OR} 2.72(95 \% \mathrm{Cl}$ 1.06-7.01: $p=0.03$ ) with 2 log likelihood of 131.54 for predicting disease outcome with $71.7 \%$ accuracy in multi-variate analysis.

Conclusion: Elevated serum CRP, LDH, ferritin and D-dimer are associated with higher mortality in patients of COVID-19 infection. Serum CRP $\geq 30 \mathrm{ng} / \mathrm{ml}, \mathrm{LDH} \geq 400 \mathrm{U} / \mathrm{L}$, ferritin $\geq 200 \mathrm{ng} / \mathrm{ml}$ and D-dimer $\geq 400 \mathrm{ng} / \mathrm{ml}$ can predict fatal outcome in COVID-19 patients.
\end{abstract}

Key Words: C-reactive protein (CRP), COVID-19 infection, D-dimer, Ferritin, Lactate dehydrogenase (LDH), Mortality.

How to cite this article: Yousaf MN, Sarwar S, Tarique S, Ahmed M, Tahir H. Mortality in Patients of COVID-19 Infection: Biochemical Markers and its Cut-off Values for Predicting Outcome. J Coll Physicians Surg Pak 2022; 32(01):37-41.

\section{INTRODUCTION}

Clinical manifestations of COVID-19 infection can vary from completely asymptomatic illness to critically lethal disease. Majority of patients are either asymptomatic or have mild influenza-like symptoms; while a certain proportion can end-up with severe pneumonia, acute respiratory distress syndrome (ARDS) or multi-organ failure, resulting in death of patient. ${ }^{1}$ Progression to severe disease is seen in $10-15 \%$ of mild cases, while $15-20 \%$ of severe patients become critical needing intensive care management. ${ }^{2}$

High mortality in critical COVID-19 infection is linked to SARS-CoV-2 infection induced activation of immune system resulting in release of cytokines including interleukin IL-6, IL-10 and tumor necrosis factor (TNF- $\alpha$ ).

Correspondence to: Dr. Shahid Sarwar, Department of Medicine, Allama Iqbal Medical College / Jinnah Hospital, Lahore, Pakistan

E-mail: shahidsarwardr@gmail.com

Received: May 23, 2021; Revised: August 18, 2021;

Accepted: October 04, 2021

DOI: https://doi.org/10.29271/jcpsp.2022.01.37
Due to this pathophysiology, plasma inflammatory markers like C-reactive protein (CRP), lactate dehydrogenase (LDH) and acute phase reactants-like serum ferritin can be used as predictors of disease severity. ${ }^{3}$ Early identification of severe form of COVID-19 infection can facilitate timely triage of patients and appropriate use of available therapeutic options to avoid potentially lethal complications. Studies have shown strong correlation between inflammatory markers and COVID-19 severity and mortality. ${ }^{4}$ However, these inflammatory markers can be raised in variety of other diseases with inflammatory response as well. Moreover, ferritin can be high in diseases like chronic kidney disease and rheumatoid arthritis. $^{5}$

SARS-CoV-2 infection can also lead to state of hypercoagulability with fatal outcome. ${ }^{6}$ Hypercoagulability is meant to prevent the escape of infectious agents in circulation with formation of fibrin micro-thrombi at alveolar level, but it results in pulmonary damage as well, precipitating disease progression and high mortality. ${ }^{7}$ D-dimer (DD) has high sensitivity for such thromboembolic events in body, but it can be raised in community acquired pneumonia and sepsis or may be normal in patients with ARDS in COVID-19 infection. ${ }^{8}$ 
Use of serum markers like CRP, LDH, serum ferritin, and DD for early prediction of severe or critical COVID-19 infection is widely being done all over the world. Moreover, recent meta-analyses have shown strong association of these inflammatory markers with severity of disease. ${ }^{9}$ However, due to low specificity, it is imperative to identify appropriate cut-off values of these markers to be used with clinical and radiological indicators of disease severity to triage these patients and to decide use of available therapeutic interventions in a timely manner; hence, avoiding development of critical stage of disease.

Different cut-off values of these inflammatory markers for predicting mortality are being proposed in literature. A systemic review of around 8,000 patients identified D-dimer value of $>532 \mathrm{ng} / \mathrm{ml}$ to be associated with severe disease; ${ }^{10}$ while data of 6,493 patients from New York City found DD level above $200 \mathrm{ng} / \mathrm{ml}$ to be a risk factor for mortality. ${ }^{11}$ Similarly, cutoff values for CRP, LDH and ferritin vary among patients of different ethnicity and region.

Therefore, the aim of this study was to determine efficacy of inflammatory markers including CRP, LDH, serum ferritin, and D-dimer in predicting mortality of COVID-19 infection in the local population; and to identify cut-off values of these markers for predicting mortality of SARS-COV-2 infection.

\section{METHODOLOGY}

This observational study approved by Institutional Ethical Review Board, was carried out at Jinnah Hospital, Lahore, from January to May 2021. Patients being admitted in high dependency unit (HDU) or intensive care unit (ICU) with history of fever along with either cough, dyspnea, flu-like symptoms, loss of smell or taste, headache, diarrhea, abdominal pain or altered sensorium; and confirmed to have COVID-19 pneumonia with positive SARS-CoV-2 reverse transcriptase polymerase chain reaction (RT-PCR) on nasopharyngeal swab or with typical findings on radiological images, i.e. pan-lobar pattern of lung involvement with multiple consolidations on X-rays chest confirmed by presence of bilateral ground-glass opacities, bronchial or interlobular septal thickening or subpleural posterior consolidations on high resolution CT (HRCT) scan, despite negative RT-PCR were included in the study.

Only patients with moderate and severe disease as defined by presence of any of these, failure to maintain 02 saturation $\geq 93 \%$ on room air, more than $50 \%$ infiltrates on radiological imaging, respiratory rate $\geq 30$ /minute, signs of respiratory distress (use of accessory muscles, failure to complete sentence or signs of central cyanosis, or a ratio of arterial partial pressure of oxygen to fraction of inspired oxygen $\left(\mathrm{PaO}_{2} / \mathrm{FiO}_{2}\right)$ $<300 \mathrm{~mm} \mathrm{Hg}$, were included in this study. ${ }^{12}$ Patients with mild disease, confirmed bacterial pneumonia, chronic kidney disease, ongoing malignancy, rheumatoid arthritis or other autoimmune diseases, were excluded. Patient having received treatment for COVID-19 in the form of steroids, remdesivir, or interleukin-6 inhibitor like tocilizumab before admission in hospital, those who left against medical advice (LAMA) or for whom results of serum biomarkers not available, were also excluded.

Minimum sample size needed for $95 \%$ confidence interval keeping margin of error at $<5 \%$ and expected mortality of $25 \%$ for moderate to severe COVID-19 patients, was 285 patients. After informed consents by patients or their first degree relatives, blood samples for baseline laboratory workup including complete blood count, liver function tests, renal function tests and markers of acute inflammation including CRP, LDH, serum ferritin and D-dimer were sent within 24 hours of admission. Serum ferritin was measured on an Architect c16000 System (Abbott Laboratories, IL) using a 2-step chemiluminescent microparticle immunoassay. The authors determined CRP and LDH in serum using the Alinity C System (Abbot Laboratories, IL), the former using a particle-enhanced immunoturbidimetric assay, the latter using spectrophotometry. D-dimer was determined on CS5100 automatic coagulation analyser (Sysmex, Kobe, Japan) by utilising a latex-enhanced photometric immunoassay (Siemens, Marburg, Germany). The D-dimer result was expressed in ng/ml FEU (Fibrinogen equivalent unit).

Patients were followed during hospital admission for disease outcome. Primary outcome measure was death of patients due to COVID-19 pneumonia-related complications or discharge from hospital after stabilisation of clinical condition.

Data was analysed using SPSS version $22{ }^{\circledR}$ (Armonk NY: IBM corp). Variables were expressed as mean \pm standard deviation (SD) for numerical variables and as percentage for nominal or categorical variables. Median \pm interquartile range (IQR) was used to express variables with non-parametric distribution. Death or discharge from hospital of patient was dependent variable; while CRP, LDH, serum ferritin and D-dimer were independent variables. Mann-Whitney U-test was used to determine association of non-parametric variables with primary outcome variable, while unpaired Student'st-test and Chi-square $\chi^{2}$ were used for numerical and nominal variables with normal distribution, respectively. Pvalue of $<0.05$ was considered significant.

For serum biomarkers with significant correlation with mortality on uni-variate analysis, ROC (Receiver operating characteristic) curve was used to determine area under curve (AUC) and for variables with $>0.70 \mathrm{AUC}$, the authors identified cut-off values with best possible sensitivity and specificity for association with mortality. After re-defining study population according to these cut-off values, binary logistic regression analysis was performed for evaluating joint association of these variables with mortality in COVID-19 infection.

\section{RESULTS}

Three hundred and eighty-six patients being admitted in HDU and ICU and fulfilling study criteria, were included in the study. Male patients were 230 (59.5\%), while 156 (40.5\%) were females. Mean age was $54.03 \pm 16.2$ years, ranging between 14-90 years. Major presenting complaint was fever, in 256 (66.3\%) patients, followed by cough in 175 (45.3\%), dyspnea in $273(70.7 \%)$, diarrhea in $56(14.5 \%)$, loss of taste in $38(9.8 \%)$, 
loss of smell in 28 (7.3\%), sore throat in 16 (4.1\%), and altered sensorium in 21 (5.4\%) patients. Diabetes mellitus was present in $184(47.7 \%)$ patients, $182(47.1 \%)$ were hypertensive, 71 (18.4\%) had pre-existing ischemic heart disease, chronic liver disease was present in $18(4.7 \%)$ patients, and 27 (7\%) patients were suffering from pre-existing lung disease.

Median hospital stay was 5 days for included patients ranging between 1-45 days. Two hundred and fifty-one (65\%) patients were discharged after clinical improvement; while 135 (35\%) died due to COVID related complications. The authors compared variables among patients who died and those who recovered, as shown in Table I. ROC curves were drawn for inflammatory markers with significantly higher values in patients who failed to survive to determine area under curve (AUC) as shown in Figure 1. AUC was 0.730 for LDH, 0.737 for CRP, 0.747 for ferritin and 0.758 for $D$-dimer.

Table I: Comparison of variables between patients who recovered and those who died of COVID-19.

\begin{tabular}{|c|c|c|c|}
\hline Variables & $\begin{array}{l}\text { Patients who died } \\
(\mathbf{n}-135) \\
\text { (Median } \pm \text { IQR) }\end{array}$ & $\begin{array}{l}\text { Discharged } \\
\text { patients } \\
(\mathrm{n}-251) \\
\text { (Median } \pm \text { IQR) }\end{array}$ & p-value \\
\hline Age & $56.5(16.32)^{*}$ & $52.68(16)^{*}$ & $0.028 \dagger$ \\
\hline ALT (IU/ml) & $31(22)$ & $31(16)$ & 0.10 \\
\hline AST (IU/ml) & $49(37)$ & $41(21)$ & 0.007 \\
\hline Prothombin time (sec) & $14.23(5.6)^{*}$ & $13.11(1.6)^{*}$ & $0.026 \dagger$ \\
\hline $\mathrm{LDH}(\mathrm{U} / \mathrm{L})$ & 702 (375) & $498(348)$ & $<0.001$ \\
\hline D-dimer (ng/ml) & $1078(643)$ & $712(406)$ & $<0.001$ \\
\hline Ferritin (ng/ml) & $810(409)$ & $593(471)$ & 0.002 \\
\hline CRP (ng/L) & $48(66)$ & $16(36)$ & $<0.001$ \\
\hline \multicolumn{4}{|c|}{$\begin{array}{l}\text { (ALT: Alanine aminotransferase, AST: Aspartate aminotransferase, LDH: Lactate } \\
\text { dehydrogenase, CRP: C-reactive protein), IQR: Inter-quartile range. } \\
* \text { Mean } \pm \text { standard deviation. } \\
t p=\text { by unpaired student's } t \text {-test. }\end{array}$} \\
\hline
\end{tabular}

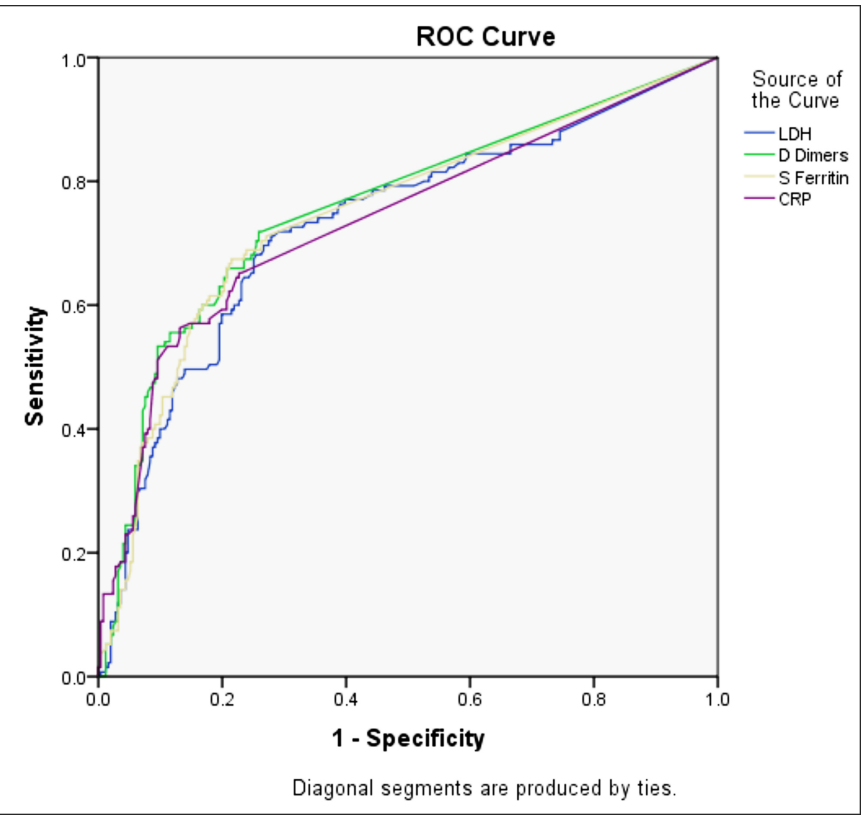

Figure 1: Receiver operating characteristic curve for variables with significant association with mortality.

Area under the curve - Test results variables: LDH .730, D dimers .758, S ferritin.747, CRP 737.

Cut-off values of these markers for association with mortality were $\mathrm{LDH} \geq 400 \mathrm{U} / \mathrm{ml}$ with odds ratio (OR) $5.37(95 \% \mathrm{Cl}$
3.01-9.57: $p=0.001), C R P \geq 30 \mathrm{ng} / \mathrm{ml}$ with OR $4.30(95 \% \mathrm{Cl}$ 2.11-8.74: $p=<0.001$ ), serum ferritin $\geq 200 \mathrm{ng} / \mathrm{ml}$ with OR 4.13 (95\% Cl 1.05-16.2: $\mathrm{p}=0.02)$ and D-Dimer $\geq 400 \mathrm{ng} / \mathrm{ml}$ with OR $2.72(95 \% \mathrm{Cl} 1.06-7.01: \mathrm{p}=0.03)$.

Model comprising of cut-off values of these four variables had 2 log likelihood of 131.54 for predicting outcome of patients with $71.7 \%$ accuracy in logistic regression analysis. Contingency Table drawn, using Hosmer and Lemeshow test, showed no significant difference in observed and predicted outcome in multi-step analysis ( $p=0.065$ ) favouring good correlation between model-based expected outcome and observed outcome of COVID-19 infection.

\section{DISCUSSION}

Early identification of severe and critical patients of COVID-19 pneumonia based on simple biochemical markers is needed to appropriately triage these patients for immediate therapeutic intervention. The authors identified CRP, serum ferritin, LDH and D-Dimer values as predictors of fatal outcome in these patients.

These markers of active inflammation are widely being used during this pandemic for risk stratification. In a study of 160 patients, area under curve (AUC) values for mortality in COVID-19 infection were 0.89 for LDH, 0.80 for CRP and 0.77 for serum ferritin. ${ }^{13}$ A regional study of 364 patients confirmed strong association of these biomarkers with mortality with AUC of 0.875 for LDH, 0.803 for D-Dimer, 0.714 for ferritin and 0.711 for CRP. Mortality in patients of that study was $27.7 \% .{ }^{14}$ In a study from Peshawar, conducted on 238 patients, AUC was $0.90,0.915$ and 0.863 for CRP, ferritin and LDH respectively. ${ }^{15}$ In the present study, AUC was 0.730 for LDH, 0.737 for CRP, 0.747 forferritin and 0.758 for D-dimer.

Despite strong evidence on prognostic value of these biomarkers, there is marked diversity in cut-off values of these markers to be used for risk stratification of patients. In a study of 191 hospitalised patients, cut-off value of D-dimer $>200 \mathrm{ng} / \mathrm{ml}$ was associated with higher mortality with OR $18.4(95 \% \mathrm{Cl}$ 2.6-128.5, $p=0.003) ;{ }^{16}$ while in another study D-dimer of more than $1000 \mathrm{ng} / \mathrm{ml}$ was identified as predictor of disease severity. ${ }^{17}$ In a study on 1,065 patients at New York City Hospital with $29.4 \%$ mortality, every $100 \mathrm{ng} / \mathrm{ml}$ increase in D-Dimer had hazard ratio (HR) of $1.06(95 \% \mathrm{Cl} 1.04-1.08, \mathrm{p}<0.0001)$ for death and HR $1.08(95 \% \mathrm{Cl} 1.06-1.10 \mathrm{p}=<0.0001)$ for intubation of patients with COVID-19 infection. ${ }^{18} \mathrm{D}$ dimer $\geq 400 \mathrm{ng} / \mathrm{ml}$ was also noted to be associated with mortality (OR $2.72,95 \% \mathrm{Cl}$ 1.06-7.01: $p=0.03$ ) in the presentstudy.

In a meta-analysis, which included 14,958 patients for ferritin and 15005 patients for D-dimer, cut-off values of these markers associated with mortality were $714 \mathrm{ng} / \mathrm{ml}$ for ferritin and 2100 $\mathrm{ng} / \mathrm{ml}$ for D-dimer and these were significantly higher in males as compared to females. ${ }^{19}$ In a meta-analysis of 64 studies, weighted mean difference (WMD) for mortality was 814.14 $\mathrm{ng} / \mathrm{ml}$ for ferritin, $66.11 \mathrm{ng} / \mathrm{ml}$ for CRP, $232.4 \mathrm{IU} / \mathrm{ml}$ for LDH and 
$574 \mathrm{ng} / \mathrm{ml}$ for D-dimer. ${ }^{20}$ In a study of 100 patients, CRP level above $30.7 \mathrm{ng} / \mathrm{ml}$ was found to have 0.838 AUC with $68.5 \%$ sensitivity and $92.3 \%$ specificity for predicting mortality. ${ }^{21}$ In a pooled analysis of 514 patients with $30.5 \%$ mortality, cut-off value of LDH for association with mortality was 245 to $253.2 \mathrm{IU} / \mathrm{ml}$ with OR 16.64 (95\% Cl: 7.07-39.13. ${ }^{22}$ The authors identified ferritin $\geq 200 \mathrm{ng} / \mathrm{ml}, \mathrm{CRP} \geq 30 \mathrm{ng} / \mathrm{ml}$ and $\mathrm{LDH} \geq 400 \mathrm{U} / \mathrm{ml}$ to be predictive of fatal patient outcome in COVID-19 patients in local population. Data of 238 patients from CMH Peshawar identified CRP $\geq 45.5 \mathrm{ng} / \mathrm{ml}$, ferritin $\geq 723 \mathrm{ng} / \mathrm{ml}$ and $\mathrm{LDH} \geq 428.5 \mathrm{U} / \mathrm{L}$ to have best sensitivity and specificity for predicting mortality. ${ }^{15}$

Diversity in cut-off values of biomarkers for predicting mortality can be due to heterogeneity of study populations or different variants of virus in different regions. However further research is needed to identify cause of this variation. Therefore, it is imperative to identify threshhold values of these biomarkers for mortality in our own population and to use those values for risk stratification along with established clinical parameters like oxygen needed to sustain saturation above $94 \%$, radiological progression of disease etc. Use of medications in COVID-19 patients is based on severity of disease and drugs like rivaroxaban, dexamethasone and remdesivir are used in moderate to severe disease patients. Selection of patients for medications based on cut-off values of biomarkers along with established parameters of disease severity will allow judicious use of these costly drugs avoiding unnecessary exposure in low risk patients.

This study only included patients being admitted in HDU and ICU. Therefore, this cohort represents patients with symptomatic illness more likely to be at severe end of disease spectrum as depicted by high mortality of $35 \%$ in this study. Absence of patients with no or mild symptoms in study cohort may lead to selection bias and limit generalisability. Furthermore, patients being admitted in hospital at different stages of their disease were included, which may compromise uniformity of data related to values of biomarkers.

Despite these limitations, this study with a large cohort of COVID-19 patients has verified efficacy of serum biomarkers for predicting patient outcome. One can use the identified cut-off values of CRP, LDH, ferritin and D-dimer in conjunction with clinical and radiological indicators for severity of disease to develop consensus on disease management plan, based on the local data.

\section{CONCLUSION}

Elevated serum CRP, LDH, ferritin and D-dimer are associated with higher mortality in patients of COVID-19 infections. Serum $\mathrm{CRP} \geq 30 \mathrm{ng} / \mathrm{ml}, \mathrm{LDH} \geq 400 \mathrm{IU} / \mathrm{L}$, ferritin $\geq 200 \mathrm{ng} / \mathrm{ml}$ and D-dimer $\geq 400 \mathrm{ng} / \mathrm{ml}$ can predict fatal outcome in COVID-19 patients.

\section{ETHICALAPPROVAL:}

This observational study was carried out at Jinnah Hospital, Lahore after approval by Institutional Ethical Review Board.

\section{PATIENTS' CONSENT:}

Informed consents by patients or their first degree relatives were obtained before the study started.

\section{CONFLICT OF INTEREST:}

The authors declared no conflict of interest.

\section{AUTHORS' CONTRIBUTION:}

MNY: Conception, data collection, revising the manuscript. SS: Design, analysis and interpretation, drafting of article.

ST: Data collection, analysis of data, revising manuscript critically.

MA: Data collection, revising manuscript critically.

HT: Data collection, revising manuscript critically.

All the authors agreed to be accountable for all aspects and approved the finalversion.

\section{REFERENCES}

1. Chen N, Zhou M, Dong X. Epidemiological and clinical characteristics of 99 cases of 2019 novel coronavirus pneumonia in Wuhan, China: A descriptive study. Lancet 2020; 395(10223):507-13. doi: 10.1016/S0140-6736 (20)30211-7.

2. Wu Z, Mc Googan JM. Characteristics of and important lessons from the coronavirus disease 2019 (COVID-19) outbreak in China: Summary of a report of 72314 cases from the Chinese center for disease control and prevention. J Am Med Assoc 2020; 323(13):1239-42. doi: 10.1001/ jama.2020.2648.

3. Gómez-Pastora J, Weigand M, Kim J. Hyperferritinemia in critically ill COVID-19 patients - is ferritin the product of inflammation or a pathogenic mediator? Clin Chim Acta 2020; 509:249-51. doi: 10.1172/jci137244.

4. Zeng F, Huang Y, Guo Y. Association of inflammatory markers with the severity of COVID-19: A meta-analysis. Int J Infect Dis 2020; 96:467-74. doi: 10.1016/j.ijid.2020. 05.055 .

5. Jacobs A, Miller F, Worwood M, Beamish MR, Wardrop CA. Ferritin in the serum of normal subjects and patients with iron deficiency and iron overload. Br Med J 1972; 4(5834): 206-8. doi: 10.1136/bmj.4.5834.206.

6. Terpos E, Ntanasis-Stathopoulos I, Elalamy I, Kastritis E, Sergentanis TN, Politou M. Hematological findings and complications of COVID-19. Am J Hematol 2020; 95(7): 834-47. doi.org/10.1002/ajh.25829.

7. Giannis D, Ziogas IA, Gianni P. Coagulation disorders in coronavirus infected patients: COVID-19, SARS-CoV-1 MERSCoV and lessons from the past. J Clin Virol 2020; 127: 104362. doi.org/10.1016/j.jcv.2020.104362.

8. Semeraro F, Ammollo CT, Caironi P, Masson S, Latini R, Panigada M. Low D-dimer levels in sepsis: Good or bad? Thromb Res 2019; 174:13-15. doi.org/10.1016/j. thromres.2018.12.003.

9. Feng $X$, Li S, Sun Q. Immune-inflammatory parameters in COVID-19 cases: A systematic review and meta-analysis. Front Med 2020; 7:301. doi: 10.3389/fmed.2020.00301.

10. Gungor B, Atici A, Baycan OF, Alici G, Ozturk F, Tugrul S, et al. Elevated D-dimer levels on admission are associated with severity and increased risk of mortality in COVID-19: A systematic review and meta-analysis. Am J Emerg Med 2021; 39:173-9. doi: 10.1016/j.ajem.2020.09.018

11. Mikami T, Miyashita H, Yamada T, Harrington M, Steinberg D, Dunn A, et al. Risk factors for mortality in patients with 
COVID-19 in New York City. J Gen Intern Med 2021; 36(1):17-26. doi: 10.1007/s11606-020-05983-z.

12. NIH: COVID-19 treatment guidelines. Available at: www.COVID19treatmentguidelines.nih.gov/overview/clinical -spectrum/

13. Payn-Pernia S, Perez LG, Sevilla AFR, Gil JS, Canales SN. Absolute lymphocytes, ferritin, C-reactive protein, and lactate dehydrogenase predict early invasive ventilation in patients with COVID-19. Lab Med 2021; 52(2):141-5. doi: 10.1093/labmed/Imaa105.

14. Asghar MS, Kazmi SJH, Khan NA, Akram M, Hassan M, Rasheed $U$, et al. Poor prognostic biochemical markers predicting fatalities caused by COVID-19: A retrospective observational study from a developing country. Cureus 2020; 12(8):e9575. doi: 10.7759/cureus.9575.

15. Arshad AR, Khan I, Shahzad K, Arshad M, Haider SJ, Aslam MJ. Association of inflammatory markers with mortality in COVID-19 infection. J Coll Physicians Surg Pak 2020; 30(10):158-63. doi: 10.29271/jcpsp.2020.supp2.S158.

16. Zhou F, Yu T, Du R, Fan G, Liu Y, Liu Z. Clinical course and risk factors for mortality of adult inpatients with COVID-19 in Wuhan China: A retrospective cohort study. Lancet 2020; 395(10229): 1054-62. doi.org/10.1016/S0140-6736 (20)305 66-3.

17. Li X, Xu S, Yu M, Wang K, Tao Y, Zhou Y. Risk factors for severity and mortality in adult COVID-19 inpatients in
Wuhan. J Allergy Clin Immunol 2020; 146(1):110-8. doi.org/10.1016/j.jaci.2020.04.006.

18. Naymagon L, Zubizarreta N, Feld J, Gerwen M, Alsen M, Thibaud S, et al. Admission D-dimer levels, D-dimer trends, and outcomes in COVID-19. Thromb Res 2020; 196:99-105. doi: 10.1016/j.thromres.2020.08.032.

19. Qeadan F, Tingey B, Gu LY, Packard AH, Erdei E, Saeed AI. Prognostic values of serum ferritin and d-dimer trajectory in patients with COVID-19. Viruses 2021; 13(3):419. doi: 10.3390/v13030419.

20. Khinda J, Janjua NZ, Cheng S, Heuvel ER, Bhatti P, Darvishian $M$. Association between markers of immune response at hospital admission and COVID-19 disease severity and mortality: A meta-analysis and metaregression. J Med Virol 2020; 93(2):1078-98. doi: 10.1002/ jmv.26411.doi: 10.1002/jmv.26411.

21. Gong, J, Dong H, Xia QS, Huang Z, Wang DK, Zhao Y, et al. Correlation analysis between disease severity and inflammation-related parameters in patients with COVID-19: A retrospective study. BMC Infect Dis 2020; 20:963. http://doi.org/10.1186/s12879-020-05681-5.

22. Henry BM, Aggarwal G, Wong J, Benoit S, Vikse J, Plebani M, et al. Lactate dehydrogenase levels predict coronavirus disease 2019 (COVID-19) severity and mortality: A pooled analysis. Am J Emerg Med 2020; 38(9):1722-6. doi.org/ 10.1016/j.ajem.2020.05.073. 